Review Article

\title{
Combining Grey Relationship Analysis and Neural Network to Develop Attractive Automobile Booth Design
}

\author{
Xinhui Kang (i) \\ School of Art and Design, Nanchang University, No. 999 Xuefu Avenue, Nanchang 330031, Jiangxi, China \\ Correspondence should be addressed to Xinhui Kang; nbukxh@163.com
}

Received 28 February 2020; Revised 14 May 2020; Accepted 19 May 2020; Published 20 June 2020

Academic Editor: Raşit Köker

Copyright ( $) 2020$ Xinhui Kang. This is an open access article distributed under the Creative Commons Attribution License, which permits unrestricted use, distribution, and reproduction in any medium, provided the original work is properly cited.

\begin{abstract}
Miryoku engineering is a design concept based on customer preferences, with the goal of creating attractive products or spaces. However, traditional Miryoku engineering faces two main issues: (1) the upper Kansei factor ranks the weights by the number of mentions, but it does not represent the importance of customers; (2) the mapping connection between the upper Kansei factor and the lower specific conditions adopts a statistical analysis method, which easily leads to the omission of key information. With the development of computer-based artificial intelligence, it repeatedly simulates human thinking with simple calculation rules, which has the advantages of fewer errors and faster speed. Therefore, on the three-level evaluation grid diagram platform established by Miryoku engineering, this paper first uses grey relationship analysis to comprehensively evaluate the priority order of Kansei words. Secondly, for the key Kansei factors, a morphological deconstruction table that connects the original reasons and specific conditions is established. Orthogonal design is used to screen representative combinations of design elements and create sample models by using the 3D software. Finally, the neural network was used to establish a mapping function between the key Kansei factors and the representative product design elements, and based on this, the most perceptually attractive product design was discovered. As a case study, the automobile booth was used to validate the effectiveness of the proposed method and significantly improve exhibitor design decisions and attendees' satisfaction.
\end{abstract}

\section{Introduction}

The purpose of production is to design an attractive product that meets customer preferences to increase market share. However, an attractive product is difficult to be defined by appropriate design elements [1-4]. Therefore, it is important to build a communication channel between the customer's charm preferences and product design elements. Miryoku engineering is one of the branches of Kansei engineering since 1998, when the Japan Society of Kansei Engineering (JSKE) was established [5]. It is also a type of ergonomic study of the relationship between metal perception and actual objects. Miryoku engineering is a research group initiated by a Japanese scholar Masato Ujigawa [6], bringing together a number of scholars. Its goal is to create attractive products, space technology, and knowledge, which is mainly to respond to the shift from the production-oriented to consumer-oriented concept, so that there is a smooth communication interface between designers and customers to develop products in the direction of customer needs. "Miryoku" is a Japanese word which means "power of attractiveness." Miryoku comes from the inner self-image, which is a kind of attraction and influence that makes people feel satisfied after they have Kansei, and then the attractive perception and memory are produced [7]. The Miryoku engineering process can be used to dig out the three-level charm factors of human-to-things, namely, the upper Kansei factor, the median original reason, and the lower specific condition (Figure 1). The evaluation structure chart established through the connection can intuitively provide a qualitative reference for the designer and can also quantify the customer's fuzzy attractive needs into specific design parameters that can be understood by the company through statistical analysis.

In the recent years, many scholars have successfully applied Miryoku engineering in the fields of car form design 


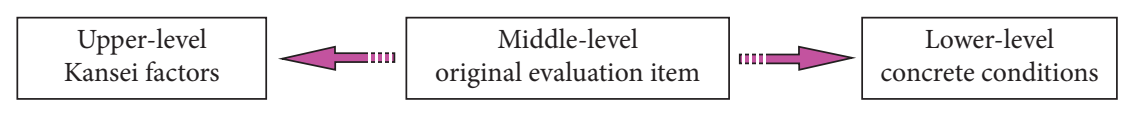

FIGURE 1: Evaluation grid diagram.

[8], ecological tourism [9], music games [10], and other fields, such as Han and Ma [11] used the method of Miryoku engineering to capture the charm factor of the stationary store. Park et al. [12] applied Miryoku engineering to analyze the user experience design of mobile hospital applications. Shen [13] and Chen et al. [14] utilized Miryoku engineering to explore the appeal of Facebook social networking service games from the perspective of game usability and functionality. People's charm experience is affected by social background, education, and aesthetics, and Miryoku engineering can perform very specific calculations on this ambiguity. However, there are still two shortcomings in the above article: (1) the extraction of the higher representative Kansei factors is mostly based on the importance of the frequency ranking mentioned in the interview process. The number of mention times is only related to the subject's feelings and cannot be linked to the importance. There are also some scholars who use the analytic network process [15] or the analytic hierarchy process [16] to calculate and rank the weight of each attractive factor, but these methods are limited by the subjective evaluation of the subject, and it is easy to have deviations in results. (2) The linear quantification method establishes a mapping function between the upper Kansei factor and the lower specific conditions. It is difficult to accurately measure the customer's nonlinear and nonnormal emotional imagery [17]. Multiple linear regression methods (e.g., quantification theory type I, QT-I) can be used to statistically predict the relationship between a Kansei classification and the design elements. Like Ho and Hou [18], Ko et al. [19] combined Miryoku engineering and QT-I to explore the attractive factors of the APP icon and the office chair. However, the linear regression method can only evaluate the relationship between length and height of linear values, and obviously it cannot measure nonlinear emotion variables. Therefore, this paper proposes the application of grey relationship analysis (GRA) and the neural network $(\mathrm{NN})$ in artificial intelligence technology to the research process of charisma to address the above problems and develops a similar product design using human logic reasoning. GRA is an important part of the grey system theory. In addition to its simplicity and accuracy, it can also convert multicriteria decision problems into quantitative analysis and comprehensive evaluation. So, GRA is used to measure the relative weight and priority of the upper evaluation items in the evaluation grid diagram. The NN can simulate the nonlinear mapping relationship with fast convergence and good local approximation effect, which solves the fuzzy and uncertain characteristics of perceptual evaluation, and makes up for the shortcomings of traditional linear methods in losing some information. Therefore, $\mathrm{NN}$ is used to establish the mapping function of Kansei factors and lower concrete design conditions. Based on this, through continuous trial and error, the product design combination with the highest Kansei evaluation value is obtained, providing theoretical guidance for companies and designers to reduce time to market and risks and significantly increase customer satisfaction.

According to the literature survey, there is no literature dedicated to the display of space design perspectives by Miryoku engineering. The display design is a comprehensive art centered on commodities, which uses effective resources to beautify commodities in a certain space. The design of a booth plays an important role to determinate a trade show success in attracting visitors and providing a positive business atmosphere [20-22]. Many auto brands have begun to pay more attention in participating in trade shows instead of the development of the car itself. When the design and interior decoration of the automobile booth are done as a way to attract attendees, customers will randomly choose the exhibition area that can arouse their own interest in addition to the subjective identification of the brands they want to visit. Therefore, an attractive automobile booth design can attract more people and then achieve the best-selling purpose and can also provide an important trading platform with suppliers. However, compared with other fields (such as graphics or architectural design), an automobile booth design does not have a sufficient theoretical basis to maintain display research and analysis. Nevertheless, few studies have examined trade show booth design and planning, dealing with the issue of commercial information transmission and reception [22]. Therefore, this paper takes the automobile booth design as a case study and combines GRA and NN to develop an attractive automobile booth design during the Miryoku engineering operation stage. In addition, a brief comparison to explain what are the similarities and differences between the research in this article and the previous ones is presented in Table 1. The main contributions of this paper can be summarized as follows:

(i) There is no study about integrating GRA and NN into Miryoku engineering process

(ii) Investigated the charm factors of the automobile booth design and derived attractive product forms

(iii) GRA measured the weight and priority of the upper abstract Kansei factor

(iv) NN replaced traditional linear analysis methods to establish a mapping relationship between Kansei factors and design languages

The organization of this paper is as follows. Section 2 reviews the previous relative works that are based on Miryoku engineering and discusses the application of GRA and NN. Section 3 briefly describes our proposed framework and depicts each step of the conducted research for the automobile booth design. Section 4 presents the analysis and discussion of the research, and Section 5 concludes this paper from the investigation. 
TABLE 1: A brief comparison between this paper and the previous ones.

\begin{tabular}{|c|c|c|c|c|c|}
\hline Literature & Expert interview & Kansei evaluation & Function evaluation & Filter product design elements & Synthesis \\
\hline This paper & EGM & GRA & & & $\mathrm{NN}$ \\
\hline Wu and Cheng [16] & EGM & Fuzzy Kano, fuzzy AHP & & & QT-I \\
\hline Wu and Kang [23] & EGM & Fuzzy AHP & & & \\
\hline Kang et al. [5] & EGM & Fuzzy Kano, fuzzy AHP & & & Fuzzy QFD \\
\hline Kang et al. [8] & EGM & & & & QT-I \\
\hline Kang et al. [24] & Focus group & & & Fuzzy Delphi & FWARM \\
\hline Chen and $\mathrm{Li}[10]$ & EGM & & & & QT-I \\
\hline Shen [13] & EGM & & & & QT-I \\
\hline Zhang et al. [15] & EGM & & & ANP & \\
\hline Wang and Hsueh [25] & & & AHP, Kano model & & DEMATEL \\
\hline Wang [26] & & & AHP, TRIZ & & QFD \\
\hline Wang [27] & Focus group & & TRIZ, FCPR & & RST \\
\hline
\end{tabular}

Notes. FWARM: fuzzy weighted association rule mining; TRIZ: theory of inventive problem solving; DEMATEL: decision-making trial and evaluation laboratory; RST: rough set theory; FCPR: fuzzy cognitive pairwise rating.

\section{Relative Work}

2.1. Miryoku Engineering. Evaluation grid method (EGM) is an important research method in Miryoku engineering. It is also a qualitative interviewing method to obtain the evaluation elements of attraction. Sanui and Inui [28] improved the psychological concepts of the repertory grid method proposed by Kelly and added two steps. Firstly, the subjects were asked to answer what they liked or disliked after comparing the samples in pairs. Then, they were asked the reasons for the favorite by additional questions, according to the meaning or conditions of the clarification of the problem to divide the hierarchy. EGM is helpful for deep understanding of the subject's psychological cognition level. Even abstract psychological feelings and subtle emotional changes that are difficult to capture can be extracted by this method. Liu et al. [29] used EGM of Miryoku engineering and fuzzy QFD to explore the design elements of a typical culture and creative product. Yamagishi et al. [30] carried out EGM of Miryoku engineering to increase the robustness of the Kansei quality and maximize customer satisfaction for consumer electronic products. Conducting qualitative EGM interviews with high-involvement groups can record and summarize the semantic structure of expert logic from the actual behavior cases of users through pairwise comparison of various features. The specific EGM operation process is briefly described as follows:

(1) Prepare relevant questions and pictures for the interview.

(2) Start a one-to-one interview and ask each respondent to divide the picture into two categories of like and dislike.

(3) Delete pictures classified as dislikes.

(4) Subjects are asked to briefly describe their favorite reasons in their own language to establish the respondents' original evaluation items or middle evaluation items.

(5) According to the original evaluation items, ask further about the abstract reasons and the specific favorite details. Then, form upper and lower evaluation items.
(6) All evaluation items are compiled into a diagram. Integrating contents of all subjects, all items are connected with straight lines to indicate the hierarchical relationships.

(7) Because there are too many high-level charm factors, this study classifies those with similar content and nature according to the $\mathrm{KJ}$ method and assigns a name to the group. Repeat this step until you can no longer group. Through this clustering process, clear charm factors can be obtained.

2.2. Grey Relationship Analysis. GRA is a measurement method to analyze the correlation between discrete sequences in the grey system theory. In incomplete information, certain data processing is used to find the correlation of data between random factor sequences. Its main purpose is to quantify the degree of correlation between factors that affect the research theme [31]. In the process of developing a product design, GRA can be used to determine the structure of the design problem and the policy of design development. Wei [32] utilized GRA based on the Kansei engineering to analyze the design of modeling and color of guide signs in the public space. Chou [33] applied GRA to determine the techniques for improving the Chinese guanxi quality of ocean freight forwarders in Taiwan. Wang [34] and Wang [35] used grey system theory to describe the weighting influence of product elements on images and words and established the transparent relationships between design elements and page images. Chen and Chuang [36] combined GRA with the Taguchi method to optimize subjective quality of customer satisfaction.

The key and difficult point of Miryoku engineering is to determine the importance of ranking the upper Kansei factors in the evaluation grid diagram. The subjective method is used to obtain the ranking of the Kansei factor based on the total number of customer mentions, but the number of mentions can only represent the degree of relevance to the target product. In response to this problem, this article introduces the grey relationship degree in the GRA into Miryoku engineering. Based on the semantic evaluation of each Kansei factor, a Kansei factor is randomly 
set as the comparison sequence, and other Kansei factors are used as the reference sequence. Kansei factors' weighting is finally determined. GRA is mainly divided into the following six calculation steps:

Step 1: determine the comparison and reference sequences:

Set $X_{o}=\left(x_{o j} \mid j=1,2, \ldots, n\right)$ as a reference sequence, also known as the parent sequence

Set $X_{i}=\left(x_{i j} \mid j=1,2, \ldots, n\right)$ as a comparison sequence, also known as the subsequence $i=1,2, \ldots, m$

Step 2: the data preprocessing method includes

(1) Measuring the effectiveness of the lower-better

$$
x^{* i j}=\frac{x_{i j}-\min _{i} x_{i j}}{\max _{i} x_{i j}-\min _{i} x_{i j}} .
$$

(2) Measuring the effectiveness of the higher-better

$$
x^{* i j}=\frac{\max _{i} x_{i j}-x_{i j}}{\max _{i} x_{i j}-\min _{i} x_{i j}} .
$$

(3) Measuring the effectiveness of the nominal-better

$$
x_{i j}^{*}=1-\frac{\left|x_{i j}-x_{\mathrm{obj}}\right|}{\max \left\{\max _{i} x_{i j}-x_{\mathrm{obj}}, x_{\mathrm{obj}}-\min _{i} x_{i j}\right\}} .
$$

Step 3: find the different sequence between the reference sequence and the comparison sequence:

$\Delta_{o i j}=\left|x_{o j}^{*}-x_{i j}^{*}\right|, \quad i=1,2, \ldots, m, j=1,2, \ldots, n$.

(4) Step 4: calculate the grey relationship coefficient:

$$
\gamma_{o i j}=\frac{\min _{\forall j} \min _{\forall j} \Delta_{o i j}+\zeta \max _{\forall j} \max _{\forall j} \Delta_{o i j}}{\Delta_{o i j}+\zeta \max _{\forall j} \max _{\forall j} \Delta_{o i j}},
$$

where $\zeta$ is the resolution factor, which is generally taken as $\zeta=0.5[36,37]$.

Step 5: calculate the grey relationship degree:

$$
\Gamma_{o i}=\sum_{j=1}^{n} w_{j} \times \gamma_{o i j}, \quad w_{j} \text { is the weight, } \sum_{j=1}^{n} w_{j}=1
$$

Step 6: arrange the grey relationship degree from small to large.

The calculated grey relationship degree is a relative weighted value. When the value is large, it indicates that the Kansei factors are more important and the designer should focus on it. On the contrary, the smaller the value is, the less important the Kansei factors are, which can be temporarily considered as an unimportant reference under the consideration of cost.

2.3. Neural Network. Neural network is an important branch of artificial intelligence. It is an information processing system that mimics the biological neural network and was created by biological inspiration from [38]. The backpropagation learning algorithm is one of the most widely used algorithms in NN models. It acquires external knowledge through learning and stores it in the network, which can solve difficult problems that are not easily handled by computers, especially language and image recognition, combined optimization calculations, and intelligent control. The feed-forward multilayer NN trained by the general BP algorithm consists of one input layer, one output layer, and one or more hidden layers. During the backpropagation process, the gradient steepest descent method is used to constantly adjust the weights and thresholds of the network to minimize the sum of squared errors of the network. Guo et al. [39] integrated $\mathrm{NN}$ and the genetic algorithm to achieve multiobjective optimization of the tricolor product color design. Wang et al. [40] constructed three NNs optimized by the genetic algorithm to predict the calculated scores of three Kansei adjectives. Misaka and Aoyama [41] applied NN to develop a design system for crack patterns on the cup surface based on Kansei. Wang et al. [42] investigated the relationships among the sneakers and the top 10 point guards by using Kansei perception and NN learning algorithms. NN can use human's nonlinear thinking methods to deal with subjective and imprecise emotional activities, so this paper uses this advantage to establish a mapping relationship between the customer Kansei charm factor and product design conditions.

\section{Proposed Research Framework}

In this study, the advantages of Miryoku engineering, GRA, and $\mathrm{NN}$ are combined to develop an attractive product design. The proposed research framework is shown in Figure 2. The study is divided into three phases: First, the expert group goes through the interview process of Miryoku engineering for a 3-level evaluation grid chart that captures high-level abstract reasons, median original evaluation items, and low-level specific design conditions. After that, GRA was used to identify the key upper Kansei factors and establish the corresponding morphological deconstruction chart for the Kansei factors with the highest grey correlation. Finally, NN is used to establish a mapping model between the key Kansei factor and the specific form of the product, and the attractive design of the automobile exhibition booth is derived based on this.

3.1. Miryoku Engineering Process. To obtain qualitative reference information, 12 high-involvement expert groups were recruited for experimental interviews. They were six males and six females, aged between 30 and 55, and all had more than five years of industrial design experience. First, 


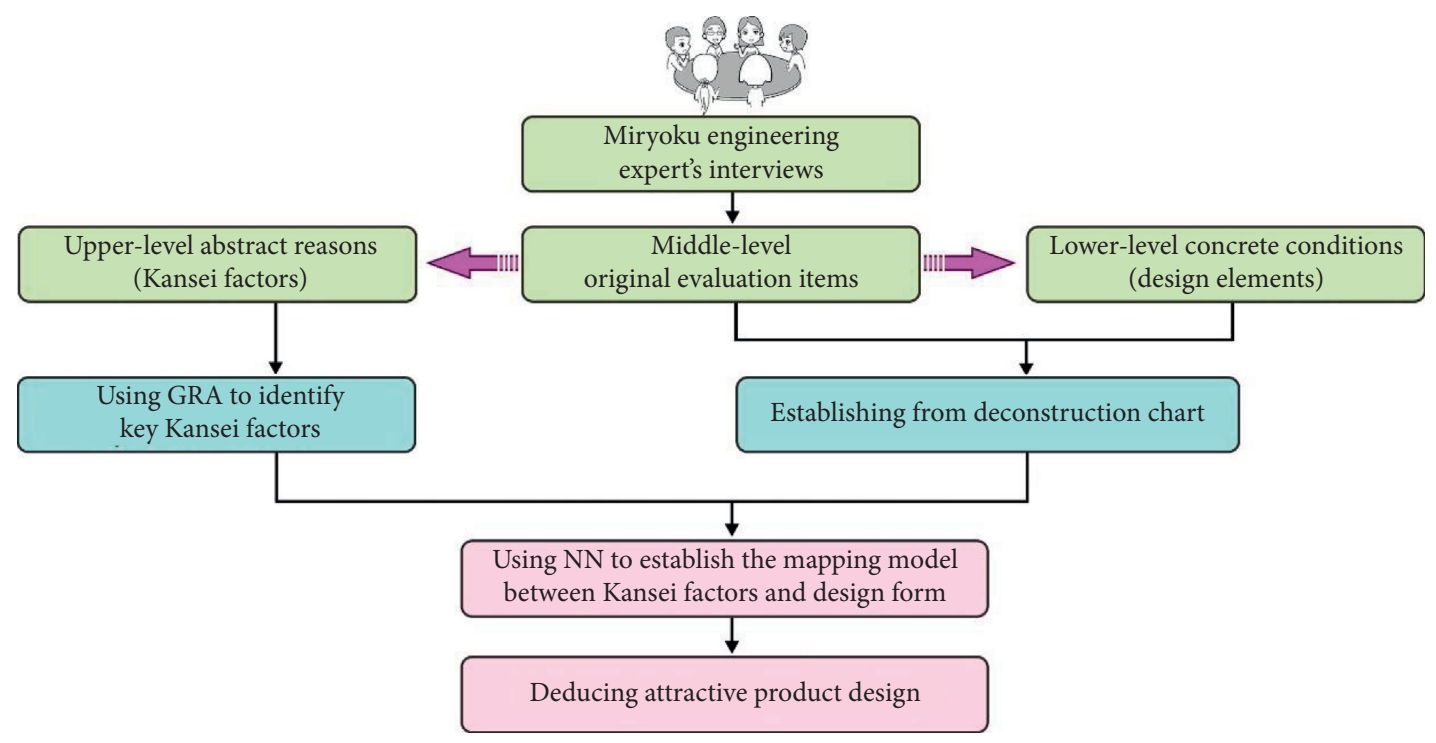

FIgURE 2: The proposed research framework.

100 models of the automobile booth design images were collected from the Internet, magazines, and other channels. After removing pixel blurring and images with large environmental impact (such as light, environmental reflections, and shadows), a total of 85 cards with a size of $10 \mathrm{~cm} \times 10 \mathrm{~cm}$ were produced. Then, the experts were invited to compare automobile booth cards with each other, and interviews were conducted from the viewpoints of pros and cons and likes and dislikes and the original reasons for preferences were refined. The time of each interview is about 50-60 minutes, and the specific questioning method is stated in the Appendix.

The above steps were repeated to complete the Miryoku engineering interview with 12 experts. A total of 174 upper Kansei factors, 20 median original reasons, and 77 lower specific conditions were extracted (Figure 3 ). To avoid too many Kansei factors from burdening the designer, the $\mathrm{KJ}$ method was used to summarize the extracted upper Kansei factors, and 16 representative perceptual words (Table 2) are summarized; a complete set was built based on them and the figure of the evaluation structure was established.

3.2. Using GRA to Identify Key Kansei Factors. This stage uses GRA to determine the weighting of each emotional vocabulary, allowing designers to gather key Kansei factors. First of all, 14 representative samples were selected from 85 automobile booth cards, and after matching with 16 perceptual factors, 100 field experts (50 men and 50 women, aged 25-55, with more than five years of design experience) were invited. A perceptual evaluation was performed, and the average evaluation values are obtained as shown in Table 3. Secondly, the "exquisite" vocabulary is set as the reference sequence and the other 15 perceptual words as the comparison sequence. Equations (1)-(6) are used to calculate the grey relationship degree (GRD) of the 15 perceptual factors. The weight values are arranged from big to small, as shown in Table 4.
The "fashionable" upper Kansei factor corresponds to six median design variables: $A$, the overall shape of the exhibition hall; $B$, the front desk shape; $C$, the ceiling shape; $D$, the background wall; $E$, the car lighting method; and F, the vehicle placement method. Among them, there are $4^{3} \times 3^{3}=1728$ kinds of automobile booth design combinations produced by 21 lower design levels (Figure 4) of six design variables. In order to avoid stereotypes or brand factors affecting the experimental results, this article will construct a new automobile booth design as a questionnaire test sample. It would take a lot of time and effort to generate so many solutions. Therefore, this paper borrows the orthogonal design in the SPSS software to obtain the optimal combination of modeling parameters. Orthogonal design is a partial factor design. Through this program, the product portfolio can be reduced to a certain range that can be processed, while maintaining orthogonality. After executing the program, 25 representative solutions are obtained to cover various design variables and levels. Graduate students of industrial design from Nanchang University used the $3 \mathrm{D}$ software to generate 25 booth design models (Figure 5). The 100 experts that are mentioned above were invited to evaluate 25 models of car display design models with a 7 -point Likert scale. A score of one indicates a low degree of fashion, a score of seven indicates a high degree, and the middle is a transition score. "Fashionable" is the Kansei evaluation index. The specific results are shown in Table 5.

3.3. Using NN to Establish the Mapping Model. This paper uses a three-layer neural network with a single hidden layer. The input layer has 21 nodes, that is, six morphological variables with a total of 21 levels. The input data are 25 design models. One node in the output layer is the "fashionable" perceptual evaluation. The number of nodes in the hidden layer generally uses the following formula: 


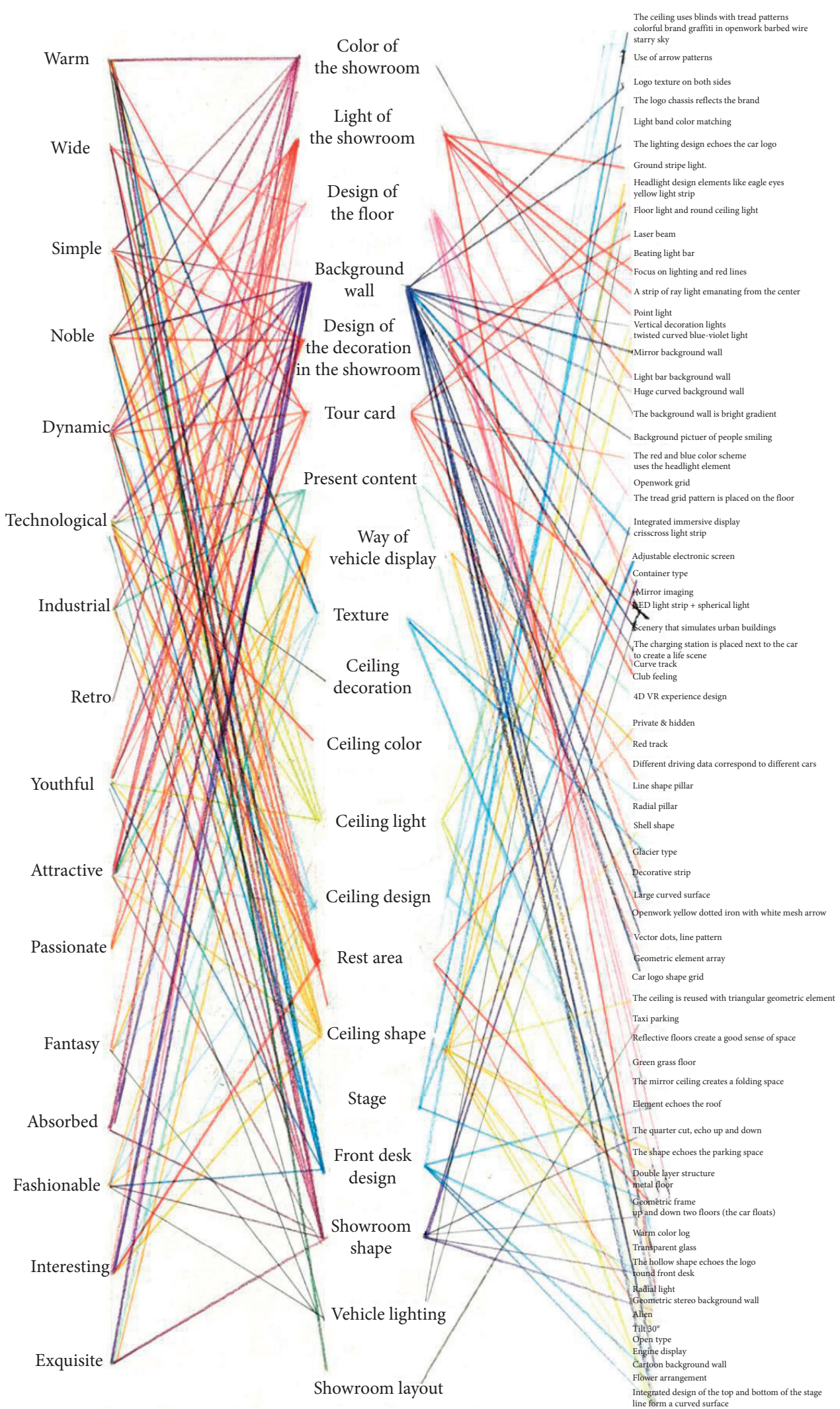

Figure 3: Complete evaluation structure chart. 
TABLE 2: 16 representative Kansei words.

\begin{tabular}{|c|c|c|c|c|c|c|c|}
\hline $\begin{array}{l}\text { Warm } \\
\text { Youthful }\end{array}$ & $\begin{array}{c}\text { Wide } \\
\text { Attractive }\end{array}$ & $\begin{array}{c}\text { Simple } \\
\text { Passionate }\end{array}$ & $\begin{array}{l}\text { Noble } \\
\text { Fantasy }\end{array}$ & $\begin{array}{l}\text { Dynamic } \\
\text { Absorbed }\end{array}$ & $\begin{array}{l}\text { Technological } \\
\text { Fashionable }\end{array}$ & $\begin{array}{l}\text { Industrial } \\
\text { Interesting }\end{array}$ & $\begin{array}{c}\text { Retro } \\
\text { Exquisite }\end{array}$ \\
\hline
\end{tabular}

TABLE 3: Kansei evaluation values.

\begin{tabular}{|c|c|c|c|c|c|c|c|c|c|c|c|c|c|c|}
\hline Kansei factors & 1 & 2 & 3 & 4 & 5 & 6 & 7 & 8 & 9 & 10 & 11 & 12 & 13 & 14 \\
\hline Warm & 3.25 & 3.45 & 3.16 & 5.63 & 4.47 & 3.75 & 3.59 & 3.90 & 3.98 & 3.90 & 3.92 & 4.43 & 3.98 & 4.12 \\
\hline Wide & 5.47 & 5.31 & 5.76 & 5.29 & 5.63 & 4.37 & 5.04 & 5.31 & 5.24 & 5.31 & 4.86 & 4.67 & 5.61 & 5.12 \\
\hline Simple & 5.59 & 5.29 & 5.61 & 4.94 & 5.35 & 4.51 & 5.31 & 5.33 & 5.31 & 4.98 & 4.71 & 4.98 & 5.49 & 5.31 \\
\hline Noble & 5.20 & 3.98 & 5.24 & 4.96 & 5.18 & 4.71 & 4.98 & 5.10 & 4.71 & 5.02 & 4.24 & 5.06 & 4.80 & 4.35 \\
\hline Dynamic & 4.86 & 3.76 & 5.94 & 3.53 & 4.51 & 5.71 & 5.45 & 4.98 & 4.53 & 5.61 & 4.16 & 5.06 & 4.96 & 4.39 \\
\hline Technological & 5.69 & 4.25 & 5.76 & 3.75 & 4.88 & 5.35 & 5.43 & 4.49 & 4.73 & 5.65 & 4.37 & 5.29 & 5.37 & 4.75 \\
\hline Industrial & 5.14 & 4.84 & 5.16 & 3.53 & 4.51 & 5.00 & 5.22 & 3.71 & 4.71 & 4.94 & 4.90 & 4.51 & 5.00 & 4.69 \\
\hline Retro & 2.33 & 2.82 & 2.75 & 3.59 & 3.35 & 3.33 & 3.29 & 4.02 & 3.43 & 3.39 & 3.61 & 3.31 & 3.37 & 3.18 \\
\hline Youthful & 5.33 & 4.73 & 5.35 & 4.69 & 4.78 & 5.20 & 5.29 & 4.24 & 4.61 & 5.35 & 4.16 & 5.10 & 5.12 & 4.63 \\
\hline Attractive & 5.08 & 4.29 & 5.51 & 4.82 & 4.94 & 5.18 & 5.22 & 4.73 & 4.55 & 5.27 & 4.29 & 5.16 & 4.98 & 4.51 \\
\hline Passionate & 4.80 & 3.96 & 5.61 & 3.96 & 4.22 & 5.25 & 5.39 & 4.86 & 4.35 & 4.92 & 4.00 & 4.76 & 4.88 & 4.18 \\
\hline Fantasy & 3.16 & 2.90 & 3.43 & 4.35 & 4.80 & 4.25 & 3.76 & 3.96 & 3.59 & 4.73 & 3.27 & 4.84 & 4.10 & 3.65 \\
\hline Absorbed & 3.86 & 3.49 & 4.41 & 4.53 & 4.57 & 4.53 & 4.49 & 4.94 & 4.33 & 5.00 & 4.12 & 4.86 & 4.53 & 4.35 \\
\hline Fashionable & 4.75 & 4.12 & 5.10 & 4.65 & 4.69 & 5.45 & 5.18 & 4.49 & 4.10 & 5.20 & 4.18 & 4.92 & 4.80 & 4.39 \\
\hline Interesting & 3.96 & 3.47 & 4.29 & 3.94 & 3.96 & 4.88 & 4.92 & 4.00 & 3.80 & 4.76 & 3.90 & 4.22 & 4.20 & 3.80 \\
\hline Exquisite & 5.00 & 4.04 & 4.71 & 5.04 & 4.86 & 5.02 & 5.04 & 3.92 & 4.61 & 5.2 & 4.16 & 4.90 & 4.90 & 4.39 \\
\hline
\end{tabular}

TABLE 4: Ranking of GRD.

\begin{tabular}{lcc}
\hline Kansei factors & GRD & Ranking \\
\hline Fashionable & 0.878 & 1 \\
Attractive & 0.871 & 2 \\
Noble & 0.865 & 3 \\
Youthful & 0.847 & 4 \\
Industrial & 0.797 & 5 \\
Dynamic & 0.790 & 6 \\
Absorbed & 0.787 & 7 \\
Passionate & 0.780 & 8 \\
Technological & 0.762 & 9 \\
Interesting & 0.726 & 10 \\
Simple & 0.707 & 11 \\
Wide & 0.705 & 12 \\
Fantasy & 0.667 & 13 \\
Warm & 0.628 & 14 \\
Retro & 0.509 & 15 \\
\hline
\end{tabular}

$$
m=\frac{n+l}{2}
$$

where $m$ is the number of nodes in the hidden layer, $n$ is the number of nodes in the input layer, and $l$ is in the output layer. Shen and Wang [43] found that when equation (7) was used to calculate the number of nodes in the hidden layer, the results were more accurate. Therefore, the number of nodes in the hidden layer is determined as $(21+1) / 2=11$.

Because design variables cannot be directly used as input parameters, specific design elements of the automobile display design need to be coded. The number of bits encoded in each sample is the same as the total number of design levels, which is 21. Each design level code has only one number as 1 , and the rest are 0 . For example, in the orthogonal experiment, the type of sample 1 in the $A-F$ design level is $4,1,2,1,3$, and 1 , respectively, then the code can be converted to 000110001001000001100 , and the codes of other samples can be obtained in the same way as input layer parameters. In addition, since the output parameters of the training function need to be in the interval $[0,1]$, while the Kansei evaluation results are obviously not completely in this interval, the Kansei evaluation values need to be normalized. This paper uses the fast linear transformation algorithm of equation (1), and after normalizing the data, it is in a suitable interval. Then, it can be imported as an output parameter into the $\mathrm{NN}$ model of the automobile booth design for training.

In this study, the first 20 samples are set as the training set, and the last five samples as the test set. Newff is used to create the NN. The activation function of the hidden layer uses a logarithmic sigmoid transfer function:

$$
f(x)=\frac{1}{1+e^{-x}}(0 \prec f(x) \prec 1) .
$$

The output layer uses a linear function purelin, the training function uses Trainlm, the number of learning is set to 10,000 , and the error is $10^{-4}$. When the training reaches 127 iterations, the training purpose is achieved and the training is stopped. So far, the NN model of the automobile booth design has been obtained (Figure 6). In order to verify the performance of the NN model, the five samples in the test set are encoded as input layer parameters, and then the output layer values are obtained. At the same time, the predicted value and the measured value are tested by RMSE. The method of calculating standard deviation is used to evaluate the performance of a model, and the root of mean square error (RMSE) is commonly used and is given as

$$
\mathrm{RMSE}=\sqrt{\frac{\sum_{i=1}^{n}\left(x_{i}-x_{0}\right)^{2}}{n}},
$$




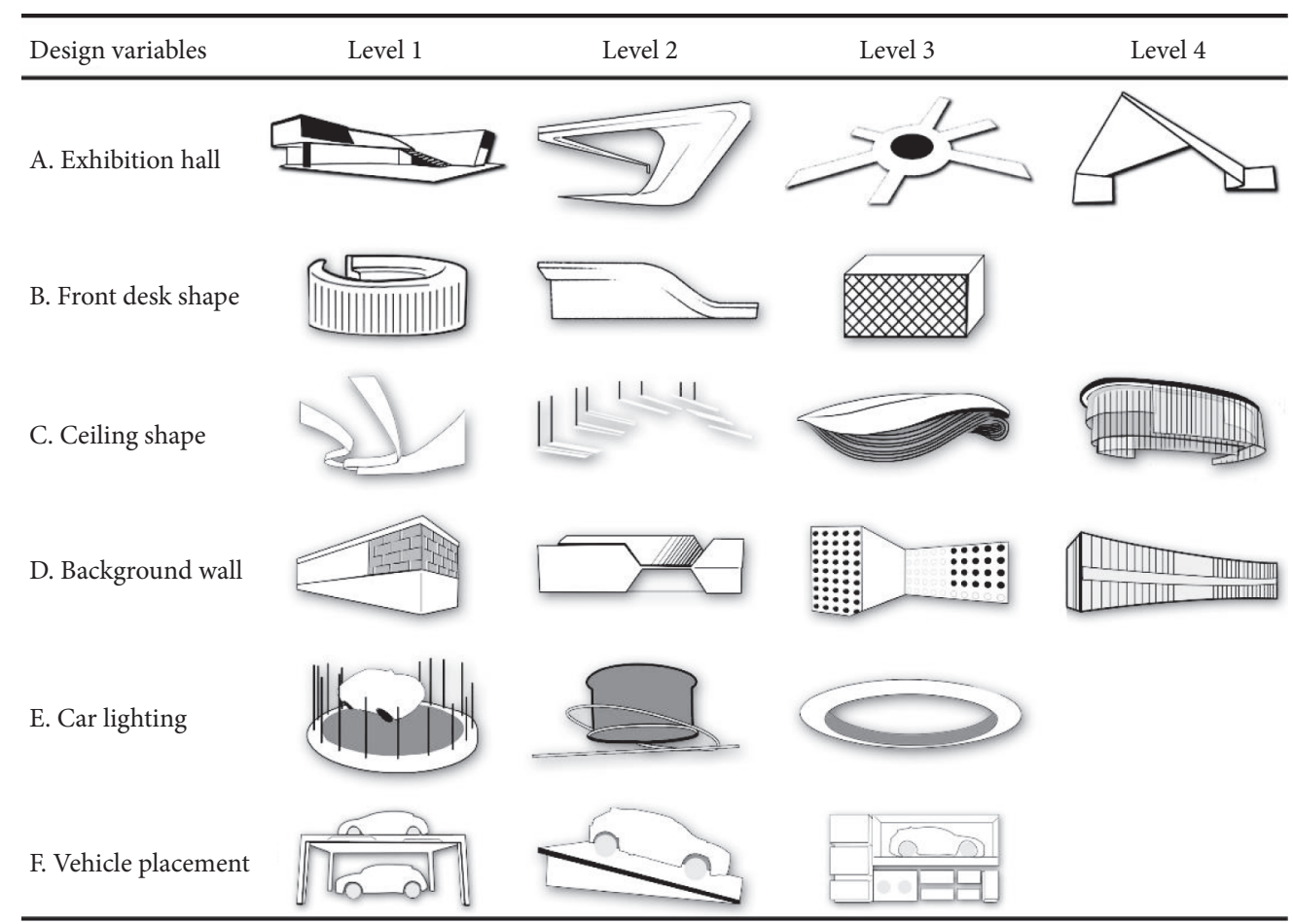

FiguRE 4: Form deconstruction chart.

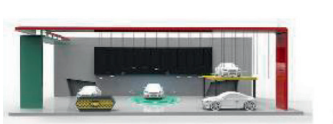

Sample 1

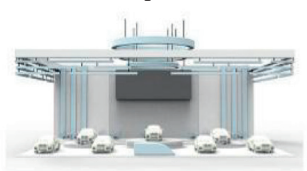

Sample 6

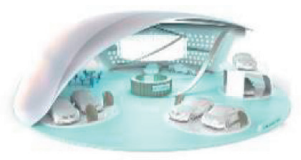

Sample 11

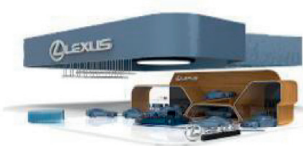

Sample 16

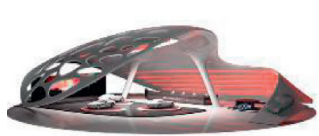

Sample 21
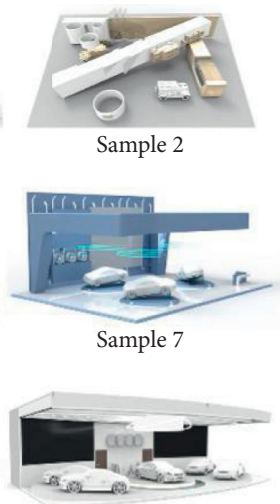

Sample 12

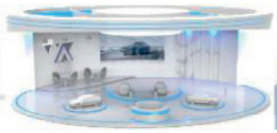

Sample 17

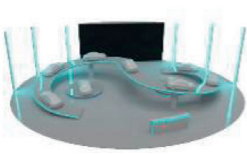

Sample 22

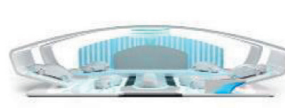

Sample 3

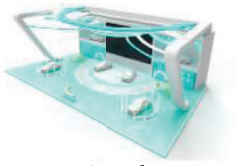

Sample 8

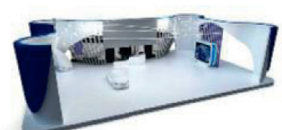

Sample 13

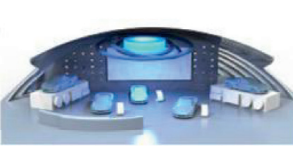

Sample 18

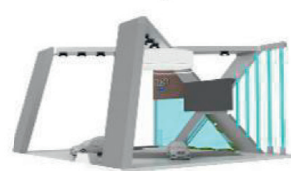

Sample 23
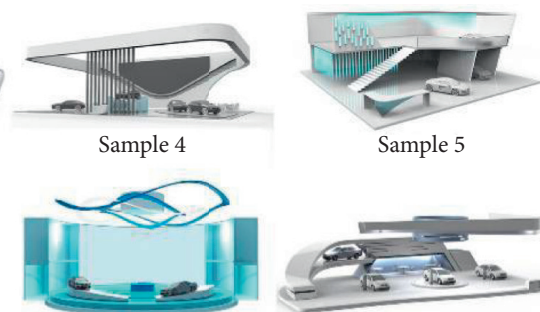

Sample 9

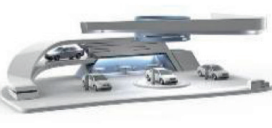

Sample 10

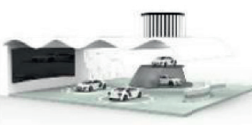

Sample 14

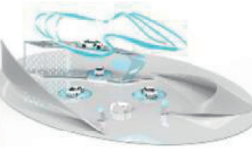

Sample 19

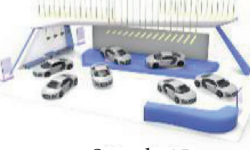

Sample 15

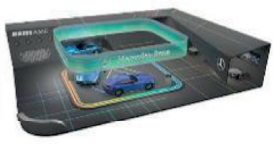

Sample 20

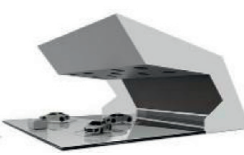

Sample 24

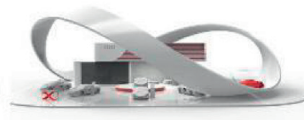

Sample 25

FIgURe 5: 25 models of the car booth design.

where $x_{i}$ is the $i^{\text {th }}$ output value predicted by the model and $x_{0}$ is the expected values assessed by the subjects in the experiment. If there is no difference or error between the output value and the expected value, the RMSE is 0 . The normalized predicted value is compared with the measured value to obtain the RMSE (Table 6). Only when the RMSE of the $\mathrm{NN}$ is small, it means that the established NN architecture can be used for prediction, judgment, and inference. Figure 7 is drawn to show a fitting diagram showing the relationship between the predicted value and the actual value 
TABle 5: Experiment layout.

\begin{tabular}{|c|c|c|c|c|c|c|c|}
\hline$U$ & $A$ & $B$ & $C$ & $D$ & $E$ & $F$ & Value \\
\hline 1 & 1 & 3 & 2 & 4 & 1 & 1 & 3.75 \\
\hline 2 & 1 & 1 & 1 & 3 & 3 & 3 & 4.91 \\
\hline 3 & 4 & 3 & 3 & 1 & 1 & 3 & 5.03 \\
\hline 4 & 4 & 2 & 4 & 3 & 1 & 1 & 4.49 \\
\hline 5 & 1 & 1 & 1 & 1 & 1 & 1 & 4.55 \\
\hline 6 & 3 & 2 & 2 & 1 & 2 & 3 & 4.06 \\
\hline 7 & 1 & 2 & 4 & 1 & 2 & 2 & 4.63 \\
\hline 8 & 2 & 2 & 1 & 2 & 1 & 3 & 4.56 \\
\hline 9 & 4 & 1 & 1 & 4 & 2 & 2 & 4.45 \\
\hline 10 & 1 & 3 & 1 & 2 & 2 & 1 & 4.74 \\
\hline 11 & 2 & 1 & 3 & 3 & 2 & 1 & 5.28 \\
\hline 12 & 2 & 2 & 1 & 4 & 1 & 2 & 3.74 \\
\hline 13 & 3 & 1 & 1 & 1 & 1 & 2 & 4.39 \\
\hline 14 & 4 & 2 & 1 & 1 & 2 & 1 & 4.44 \\
\hline 15 & 1 & 2 & 2 & 3 & 1 & 2 & 3.53 \\
\hline 16 & 4 & 1 & 2 & 2 & 3 & 2 & 4.46 \\
\hline 17 & 3 & 1 & 4 & 2 & 1 & 1 & 4.19 \\
\hline 18 & 3 & 3 & 1 & 3 & 2 & 2 & 4.40 \\
\hline 19 & 2 & 1 & 2 & 1 & 2 & 1 & 5.39 \\
\hline 20 & 1 & 1 & 4 & 4 & 2 & 3 & 4.64 \\
\hline 21 & 1 & 1 & 3 & 1 & 1 & 2 & 4.73 \\
\hline 22 & 1 & 2 & 1 & 1 & 3 & 1 & 4.93 \\
\hline 23 & 2 & 3 & 4 & 1 & 3 & 2 & 4.58 \\
\hline 24 & 3 & 2 & 3 & 4 & 3 & 1 & 4.79 \\
\hline 25 & 1 & 2 & 3 & 2 & 2 & 2 & 5.03 \\
\hline
\end{tabular}
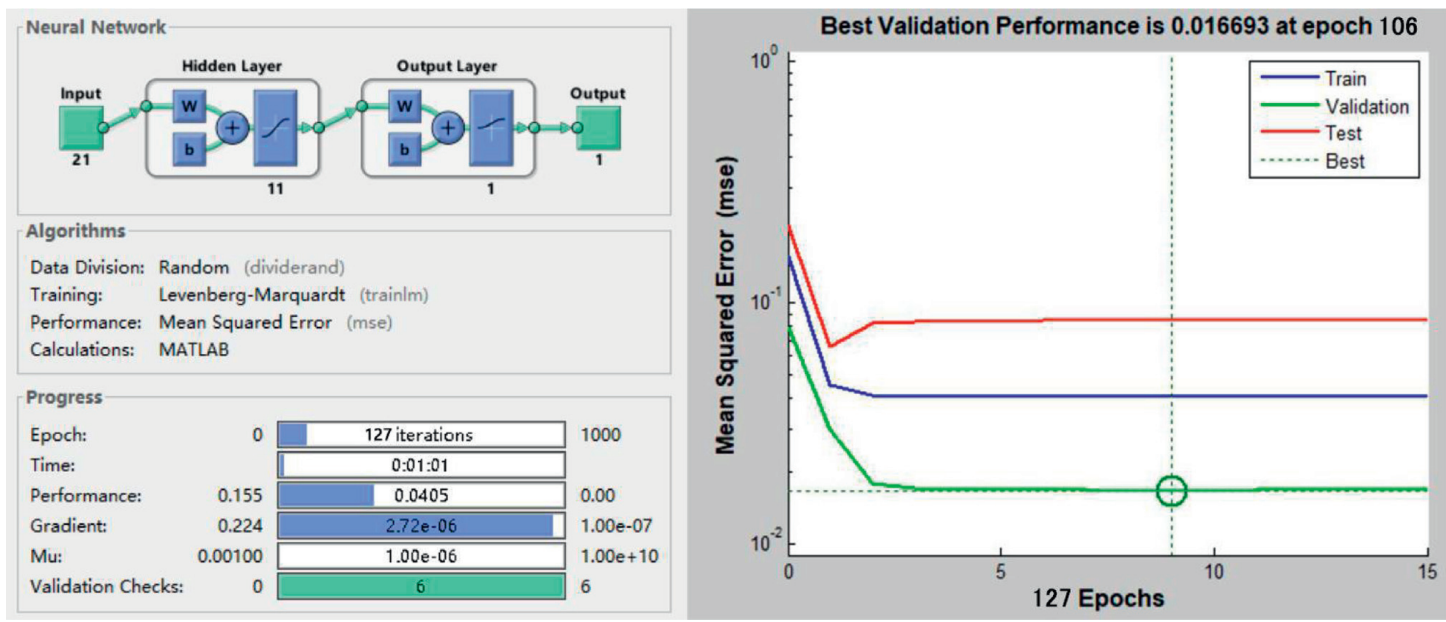

Figure 6: The performance of NN.

TABLE 6: NN model verification.

\begin{tabular}{lcccccc}
\hline & No. 21 & No. 22 & No. 23 & No. 24 & No. 25 & RMSE \\
\hline $\begin{array}{l}\text { Expected } \\
\text { values }\end{array}$ & 4.73 & 4.93 & 4.58 & 4.79 & 5.03 & 0.3134 \\
$\begin{array}{l}\text { Predicted } \\
\text { values }\end{array}$ & 4.4724 & 5.0519 & 4.6342 & 4.8727 & 4.9427 & \\
\hline
\end{tabular}

of the output of the NN model. This result shows that the model has good consistency.

Based on the trained NN model, 1728 kinds of morphological combinations of the automobile booth design are imported into the computer as input layer parameters, and the Kansei evaluation values that are corresponding to each combination are calculated. The output layer parameter codes of the top three items with the highest "fashionable" perceptual evaluation value after operation are 233233 (Kansei value: 4.4704), 213233 (Kansei value: 4.4619), and 333231 (Kansei value: 4.4614), and the corresponding best design element combinations are 010000100100100001001, 010010000100100001001, and 001000100100100001100. According to the form combination corresponding to the highest perceptual evaluation value, the design of the automobile booth design is as shown in Figure 8. Finally, the 


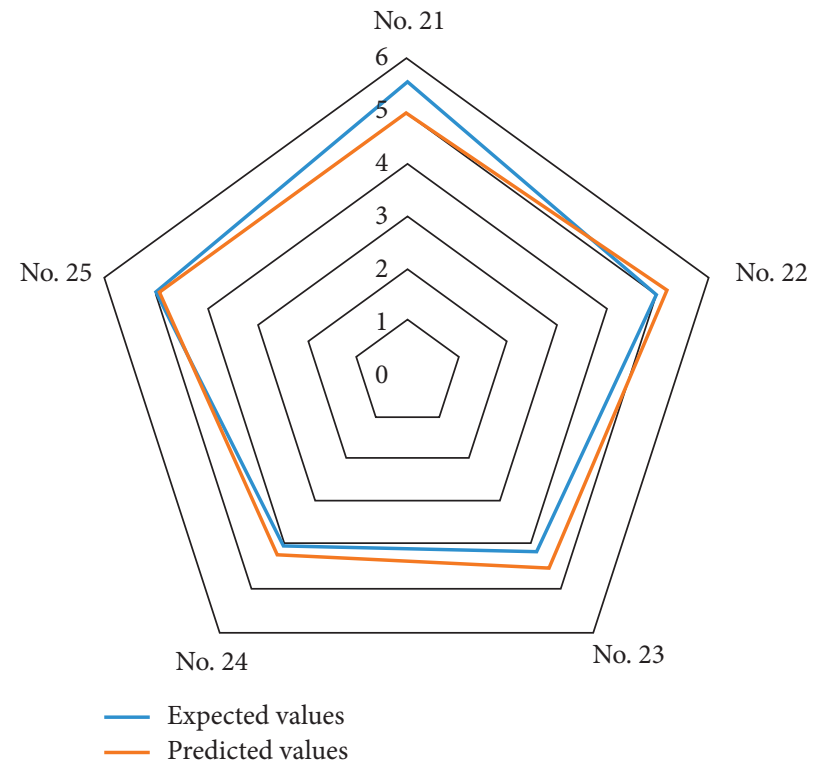

Figure 7: The radar map for validation.

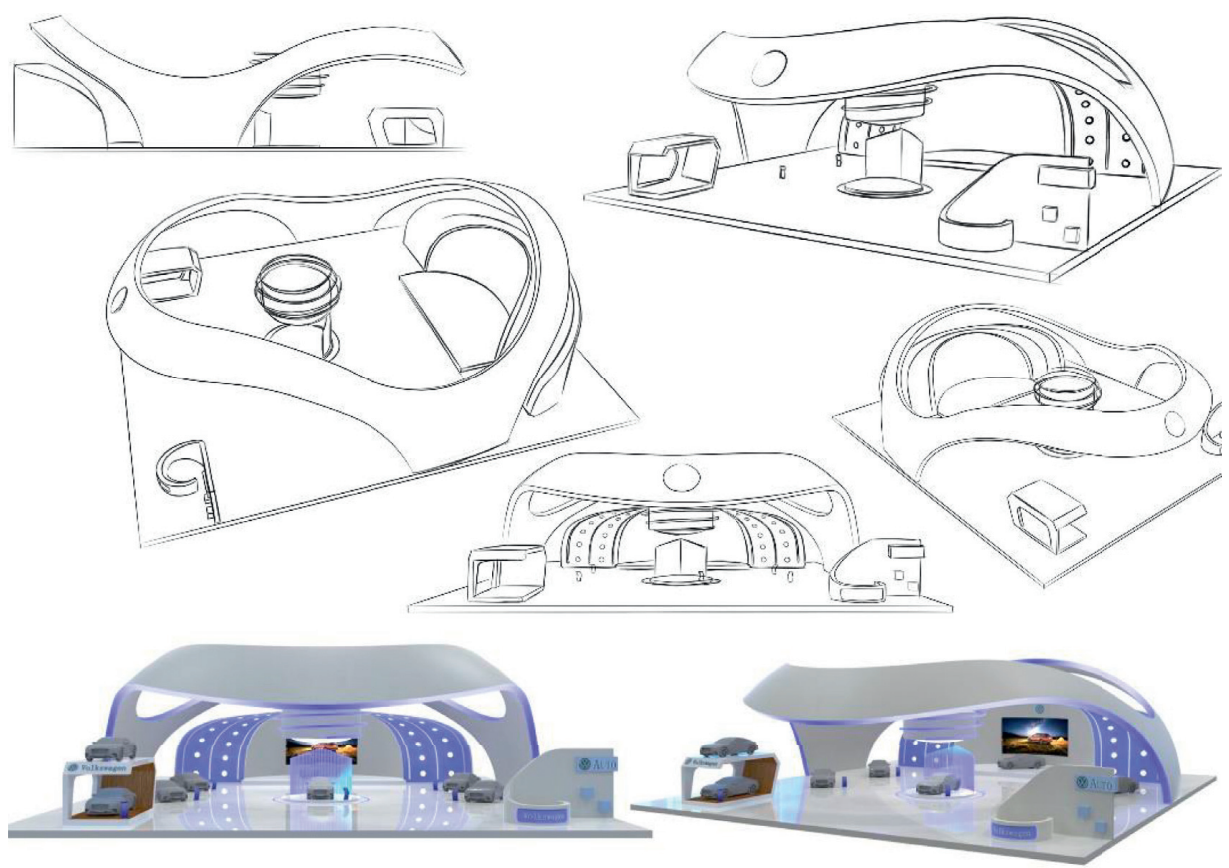

Figure 8: Novel design of the car booth.

abovementioned 100 expert groups are invited again to implement a seven-point Likert scale on the design plan, and a "fashionable" Kansei evaluation value of 6.238 was obtained, which is significantly higher than the average of 3.5 points, so it illustrates the attractive product developed by the proposed combination model design has met customer preferences.

\section{Analysis and Discussion}

Compared with traditional Miryoku engineering methods, combining GRA and NN can achieve the weight ranking of upper Kansei factors and establish a nonlinear mapping function between upper and lower specific conditions, which solves the problem that Miryoku engineering can only provide customer preferences and the qualitative relationships between design elements. This paper executes the operation process of Miryoku engineering first to obtain 16 higher-level abstract Kansei factors, which express the user's glamour and emotional experience on the car display design. In order to distinguish the importance of these emotional elements, GRA was used to replace the simple operations of the previous sum of mentions, Kano model, or AHP method. The weight of the Kansei index was measured using the concept of grey correlation. It is found that the top three 


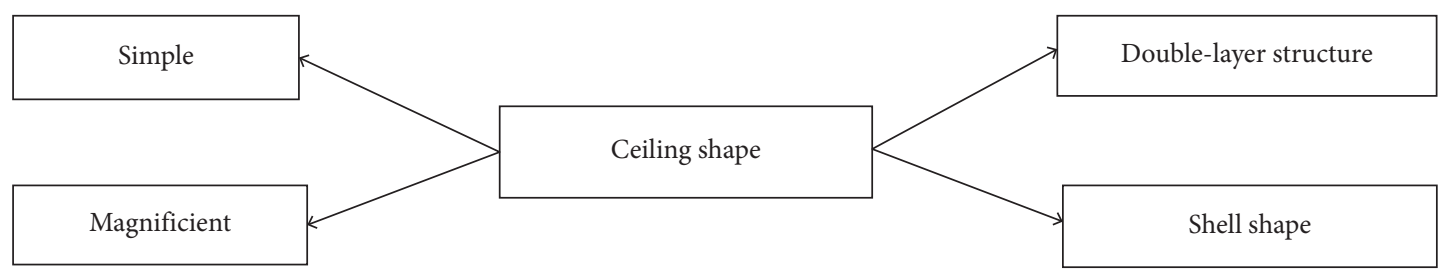

Figure 9: A single evaluation project construction diagram.

factors include fashionable (0.878), attractive (0.871), and noble (0.865) and the last three factors include retro (0.509), warm (0.628), and fantasy (0.667). This result shows that users attach the greatest importance to the innovative form of the automobile exhibition booth, and the fashionable product shape is still the soul of the design. Secondly, the noble and attractive booth design is easy to attract users' attention, and designers should give priority to these users' emotional preferences. On the contrary, the retro style of the booth is the least likely to be loved by users. At the same time, designers can ignore the warm and fantasy emotional images under the premise of limited resources.

With the rapid development of the global economy, car manufacturers have gradually attached more importance to the sales process than the development of the performance of the car itself. Various forms of exhibitions, sales, annual meetings and other exhibitions are in line with the needs of the entire social and economic development. This paper evaluates the charismatic characteristics of the automobile booth design in the market and investigates the quantitative relationship between the customer's abstract Kansei factor and booth design elements. Finally, the combination of the best perceptual evaluation was selected from more than a thousand design form combinations, that is, the combination of $A 2+B 3+C 3+D 2+E 3+F 3$, and based on this, the most innovative automobile booth can be designed. In this paper, GRA and NN in artificial intelligence technology are used to accurately calculate the mapping function between the weight of the upper abstract sensation and the corresponding lower specific design conditions in the Miryoku engineering process. Therefore, designers can focus on the attractive factors of customer preferences obtained from the research results and formulate new product development strategies in a planned way to shorten the time of research and improve customer satisfaction.

\section{Conclusion}

In the fierce global auto sales market, an excellent automobile booth design can distinguish its own products from many homogeneous competitions, attract more visitors to stay, and increase product sales. The main purpose of this study is to develop an attractive automobile booth design combined with GRA and NN on the evaluation structure map platform established by Miryoku engineering. First, Miryoku engineering obtained 16 representative upper-level Kansei factors, 20 original reasons, and 77 lower-level specific design conditions based on a survey of 12 experts' group. Secondly, in artificial intelligence technology, GRA is used to replace the traditional frequency summing method, and the key Kansei factors are obtained by using the calculation method of the grey relationship degree. In the end, NN was used to establish a mapping relationship between the key Kansei factors and the corresponding design elements of the automobile booth shape and explore the optimal design to enhance the attractiveness of the automobile booth layout.

The limitation of this research is as follows. First of all, although the hierarchical structure of expert opinion, which is extracted by Miryoku engineering, is detailed and exquisite, it may be difficult to comprehensively record the subjective emotions by using only adjectives. Secondly, $\mathrm{NN}$ is always criticized for its black-box property, and other artificial intelligence technologies such as rough set theory and support vector machine can be applied in the future. After these, people's preference factors are different because of different genders, education levels, and occupations, so studies can be grouped based on demographic variables. Last, this paper only considers the morphological changes of the booth design, and the future research scope should be expanded to over booth size, finish materials, lighting, and signage.

\section{Appendix}

Specific questionnaire in EGM:

(1) The specific questioning method in Section 3.1 is stated as follows:

Q1: “Do you prefer sample 10 or sample 15?”

Answer: "I prefer sample 15"

Q2: "Why do you prefer sample 15?"

Answer: "Because of the ceiling shape of sample 15 !”

After determining the median original reason preferred by the subject, continue to question the upper abstract reason of ladder up and the specific details of its composition ladder down.

(1) Ladder up: continue to ask high-level abstract reasons for "ceiling shapes."

Q3: Why do you like the "ceiling shape" of sample 15 ?"

Answer: Because it looks "simple and magnificent" 
(2) Ladder down: based on the "ceiling shape", continue to ask the testers about the specific design elements that constitute a "simple and atmospheric ceiling shape" and analyze the physical properties of the automobile booth that the testers love.

Q4: What design factors make you feel the simplicity of the ceiling?

Answer: "Double-layer structure" and "Shell shape" From the above questioning method, a three-level structure diagram of the upper abstract reason for the evaluation item, the median original evaluation item, and the lower specific conditions is organized (Figure 9).

\section{Data Availability}

The experiment data used to support the findings of this study are included in the article.

\section{Conflicts of Interest}

No potential conflicts of interest are reported by the author.

\section{References}

[1] K.-C. Wang, "Product design prediction using integrated dynamic Kansei engineering scheme," Journal of Internet Technology, vol. 15, no. 7, pp. 1217-1225, 2014.

[2] M. R. Reddy, K. G. Srinivasa, and B. E. Reddy, "Smart vehicular system based on the internet of things," Journal of Organizational and End User Computing, vol. 30, no. 3, pp. 45-62, 2018.

[3] P. Singh and R. Agrawal, "A customer centric best connected channel model for heterogeneous and iot networks," Journal of Organizational and End User Computing, vol. 30, no. 4, pp. 32-50, 2018.

[4] T. Grubljesic, P. S. Coelho, and J. Jaklic, "The shift to socioorganizational drivers of business intelligence and analytics acceptance," Journal Of Organizational And End User Computing, vol. 31, no. 2, pp. 37-64, 2019.

[5] X. Kang, M. Yang, Y. Wu, and B. Ni, "Integrating evaluation grid method and fuzzy quality function deployment to new product development," Mathematical Problems in Engineering, vol. 2018, Article ID 2451470, 2018.

[6] M. Ujigawa, "The evolution of preference-based design," Research and Development Institute, vol. 46, pp. 1-10, 2000.

[7] M. Ma, Y. Chen, and S. Li, "How to build design strategy for attractiveness of new products (DSANP)," Advances in Information Sciences and Service Sciences, vol. 3, no. 11, pp. 17-26, 2011.

[8] X. Kang, M. Yang, W. Yang, and Y. Wu, "Research on the form design of mini car in perceptual consumption times," in Proceedings of the Design, User Experience, and Usability: Theory, Methodology, and Management-6th International Conference, vol. 10288, LNCS, Vancouver, Canada, pp. 258271, 2017.

[9] B. Hong and M.-Y. Ma, "Exploration of the charm factors of ecological tourism," EKOLOJI, vol. 28, no. 107, pp. 937-944, 2019.

[10] Y.-C. Chen and S.-R. Li, "Cognition difference between players of different involvement toward the concrete design features in music games," Plos One, vol. 14, no. 5, Article ID e0216276, 2019.

[11] J. X. Han and M.-Y. Ma, "The study of charm factor of stationery shop," Journal of Interdisciplinary Mathematics, vol. 21, no. 2, pp. 299-305, 2018.

[12] J. Park, J.-H. Kim, E.-J. Park, and S. M. Ham, “Analyzing user experience design of mobile hospital applications using the evaluation grid method," Wireless Personal Communications, vol. 91, no. 4, pp. 1591-1602, 2016.

[13] K. S. Shen, "Measuring the sociocultural appeal of SNS games in Taiwan," Internet Research, vol. 23, no. 3, pp. 372-392, 2013.

[14] K. H. Chen, K. S. Shen, and M. Y. Ma, "The functional and usable appeal of Facebook SNS games," Internet Research, vol. 22, no. 4, pp. 467-481, 2012.

[15] Y. Zhang, S.-F. Liu, and K. Wang, "Explorations of charm factors and development of fishing in southern taiwan based on miryoku engineering and the analytic network process," Sustainability, vol. 11, no. 3, p. 737, 2019.

[16] Y. Wu and J. Cheng, "Continuous fuzzy kano model and fuzzy AHP model for aesthetic product design: case study of an electric scooter," Mathematical Problems in Engineering, vol. 2018, Article ID 4162539, 13 pages, 2018.

[17] M. Nagamachi, Y. Okazaki, and M. Ishikawa, "Kansei engineering and application of the rough sets model," Proceedings of the Institution of Mechanical Engineers, Part I: Journal of Systems and Control Engineering, vol. 220, no. 8, pp. 763-768, 2006.

[18] C.-H. Ho and K.-C. Hou, "Exploring the attractive factors of app icons," KSII Transactions on Internet and Information Systems, vol. 9, no. 6, 2015.

[19] Y.-C. Ko, C.-H. Lo, and C.-C. Chen, "Influence of personality traits on consumer preferences: the case of office chair selection by attractiveness," Sustainability, vol. 10, no. 11, p. 4183, 2018.

[20] P. H. Bloch, S. Gopalakrishna, A. T. Crecelius, and M. Scatolin Murarolli, "Exploring booth design as a determinant of trade show success," Journal of Business-To-Business Marketing, vol. 24, no. 4, pp. 237-256, 2017.

[21] S. Chung, "A study on Korean style exhibition booth design through joinery techniques," A Journal of Brand Design Association of Korea, vol. 14, no. 4, pp. 257-266, 2016.

[22] M.-S. Huang, H.-C. Tsai, and T.-H. Huang, "Applying Kansei engineering to industrial machinery trade show booth design," International Journal of Industrial Ergonomics, vol. 41, no. 1, pp. 72-78, 2011.

[23] Y. Wu and X. Kang, "Establishment of an aggregation model associated with instrument interface design based on Kansei factors of electric vehicle drivers," Mathematical Problems in Engineering, vol. 2020, Article ID 8315641, 15 pages, 2020.

[24] X. Kang, C. S. Poter, and B. Erik, "Using the fuzzy weighted association rule mining approach to develop a customer satisfaction product form," Journal of Intelligent \& Fuzzy Systems, vol. 38, no. 4, pp. 4343-4357, 2020.

[25] C.-H. Wang and O.-Z. Hsueh, "A novel approach to incorporate customer preference and perception into product configuration: a case study on smart pads," Computer Standards \& Interfaces, vol. 35, no. 5, pp. 549-556, 2013.

[26] L.-X. Wang, "A new look at type-2 fuzzy sets and type-2 fuzzy logic systems," IEEE Transactions on Fuzzy Systems, vol. 25, no. 3, pp. 693-706, 2017.

[27] C.-H. Wang, "Combining rough set theory with fuzzy cognitive pairwise rating to construct a novel framework for 
developing multi-functional tablets," Journal of Engineering Design, vol. 29, no. 8-9, pp. 430-448, 2018.

[28] J. Sanui and M. Inui, "Phenomenological approach to the evaluation of places: a study on the construct system associated with place evaluation: 1," Journal of Architecture, Planning and Environmental Engineering (Transactions of AIJ), vol. 367, pp. 15-22, 1986.

[29] S. Liu, Y. Zhang, Y. Lai, and M. Wang, "A novel method of design elements based on EGM and fuzzy QFD," International Journal of Product Development, vol. 22, no. 5, pp. 408-420, 2018.

[30] K. S. Yamagishi and H. Nishimura, "Requirement analysis considering uncertain customer preference for Kansei quality of product," Journal of Advanced Mechanical Design, Systems, and Manufacturing, vol. 12, no. 1, pp. 1-13, 2018.

[31] J. Deng, Grey Prediction and Decision Making, Huazhong University of Technology Press, Wuhan, China, 1986.

[32] Y. Wei, "Form factors of modeling language under different color schemes with grey relational analysis based on entropy method," International Journal of Pattern Recognition and Artificial Intelligence, vol. 33, no. 8, p. 1950011, 2019.

[33] T.-Y. Chou, "Identifying techniques for improving Chinese guanxi quality of ocean freight forwarders in Taiwan," Journal of Marine Science and Technology-Taiwan, vol. 26, no. 2, pp. 207-216, 2018.

[34] K.-C. Wang, "A hybrid Kansei engineering design expert system based on grey system theory and support vector regression," Expert Systems with Applications, vol. 38, no. 7, pp. 8738-8750, 2011.

[35] K.-C. Wang, "The evaluation of E-commerce homepage design through grey-based Kansei engineering scheme," The Journal of Grey System, vol. 4, pp. 391-404, 2011.

[36] C.-C. Chen and M.-C. Chuang, "Integrating the Kano model into a robust design approach to enhance customer satisfaction with product design," International Journal Of Production Economics, vol. 114, no. 2, pp. 667-681, 2008.

[37] L. Wu, H. Gao, and K.-C. Wang, "A green-IKE inference system based on Grey Neural network model for humanized sustainable feeling assessment about products," Mathematical Problems in Engineering, vol. 2020, Article ID 6391463, 9 pages, 2020.

[38] K. Hirasawa, H. Eto, J. Hu, J. Murata, and Q. Xiong, "Universal Learning Networks with varying parameters considering branch control," IEEJ Transactions on Electronics, Information and Systems, vol. 121, no. 1, pp. 98-105, 2001.

[39] F. Guo, F. Li, M. Nagamachi, M. Hu, and M. Li, "Research on color optimization of tricolor product considering color harmony and users' emotion," Color Research \& Application, vol. 45, no. 1, pp. 156-171, 2020.

[40] Z. Wang, W. Liu, M. Yang, and D. Han, "A multi-objective evolutionary algorithm model for product form design based on improved SPEA2," Applied Sciences, vol. 9, no. 14, p. 2944, 2019.

[41] M. Misaka and H. Aoyama, "Development of design system for crack patterns on cup surface based on kansei," Journal of Computational Design and Engineering, vol. 5, no. 4, pp. 435-441, 2018.

[42] C.-C. Wang, C.-H. Yang, C.-S. Wang, T.-R. Chang, and K.-J. Yang, "Feature recognition and shape design in sneakers," Computers \& Industrial Engineering, vol. 102, pp. 408-422, 2016.

[43] H.-C. Shen and K.-C. Wang, "Affective product form design using fuzzy Kansei engineering and creativity," Journal of Ambient Intelligence And Humanized Computing, vol. 7, no. 6, pp. 875-888, 2016. 